\title{
Implementation of the Process of Recognising Education Effects Obtained in Non-Formal and Informal Education Systems in Higher Education Institutions in Poland
}

\author{
Ph. D. Grażyna Voss \\ Institute of Accounting, Torun School of Banking, Poland \\ Email: gvoss@wp.pl \\ Ph. D. Piotr Prewysz-Kwinto \\ Institute of Finance and Banking, Torun School of Banking, Poland \\ Email: ppqq@poczta.onet.pl
}

\section{Doi:10.5901/jesr.2013.v3n7p249}

\section{Abstract}

\begin{abstract}
The decision of the European Commission obliges all of the EU member states to prepare and implement the process of recognising the effects of education obtained in non-formal and informal systems in higher education. The progress is varied in different countries and Poland is preparing to create the procedures and implement the changes. The knowledge and expectations of the employers regarding this process are the subject of research and are aiming at familiarising the academic environment with the possibility of implementing the effects of education in order to make the studies more practical and prepare the graduates to actively enter the job market. The objective of the paper is to present the results of surveys presenting the knowledge, expectations and areas of industry-academia cooperation in the scope of implementing the process of recognition in higher education in Poland in the Finance and Accounting teaching module.
\end{abstract}

\section{Introduction}

The competitiveness on the job market is the reason why the public and private higher education institutions undertake various actions aiming at offering additional services for their students. They diversify the educational offer by creating new courses for which there is a demand on the job market (Horynia \& Maciejewski, 2007). The directions of changes in the educational polity were presented by the European Commission in the year 1995 in the White Paper on Education and Training. The authors of the paper refer to the learning society and present five preconditions for the realisation of the "new education", which are: (Cresson \& Flynna 1997)

1. Encouraging to obtain new skills,

2. Bringing the school and enterprise closer,

3. Limiting marginalisation (or some environments),

4. Popularising the knowledge of three languages,

5. Equal treatment of material and educational investments.

It should be emphasised that the globalisation creates new opportunities for the well-educated and simultaneously discriminates the lack of knowledge, skills and social competences. If a society does not notice those trends it pushes it to the margin of work life.

The introduction of the National Qualification Framework by the Polish Ministry of Science and Higher Education forced the higher education institutions to prepare new systems of evaluation by defining the effects of education (knowledge, skills, social competences), which the students are to acquire in higher education. This has also allowed popularising the non-formal and informal education in Poland, which has been widely unnoticed. The non-formal and informal education is defined as: ${ }^{1}$

- non-formal education is: learning resulting from actions which are planned but not intended as obvious components of the education process (in the categories of educational objectives, the time spent for teaching or the didactic support), which nonetheless has an effect of learning. Such actions are intentional from the

1 Terminology of European education and training policy, CEDEFOP 2008. See also: S. E. Eaton, Formal, non-formal and informal learning: The case of literacy, essential skills and language in Canada, Calgary, 2010r. s.8 
point of view of the learner. Usually it does not result in a certificate being issued.

- informal education is: learning results from actions relating to work, family life or spending free time. It is unorganised, unstructured when it comes to objectives, duration time, pedagogical support. It is unintentional from the point of view of the learner. It does not lead to certification.

According to the recommendation of the Council of the European Union from 5.09.2012 concerning the validation of non-formal and informal education, all of the Member States should assure the existence of the national validation system by the year 2015, which would allow the higher education institutions to recognise the effects of education obtained outside of the formal education system. At present in Poland there is no legal basis which would allow recognition of education effects, but the works towards this aim are gathering pace and aim at complex solutions concerning legal conditions (regarding implementing uniform legal regulations destined to propagate the process of recognition with simultaneous referral to the control of education in order to assure adequate quality of education, organisational (maintaining the autonomy of higher education institutions in the area of preparing respective regulations and procedures in this area) and creating the necessary tools allowing the measurement of the education effects obtained outside of the formal education.

Dissemination of the recognition process of taking into account the education effects obtained in a system outside of the formal one will allow increasing the amount of persons increasing their education thanks to the possibilities of:

- exemption from some of the subjects/modules,

- decrease of the studying fees,

- shortening of the time needed for obtaining education.

The knowledge and expectation of the employers relating to this process are subject of research and are aiming at familiarising the academic environment with the possibility of implementing the effects of education in order to make the studies more practical and prepare the graduates to actively enter the job market.

The objective of the paper is to present the results of surveys presenting the knowledge, expectations and areas of industry-academia cooperation in the scope of implementing the process of recognition in higher education in Poland in the Finance and Accounting teaching module.

\section{Characteristic and the method of the research}

The research took into account the employers form the Pomorskie and Kujawsko-Pomorskie regions. The participants were the micro, small, medium and large enterprises ${ }^{2}$, which expressed willingness and are the employers of students who study Finance and Accounting part time. The study was carried out between 10th and 31st April 2013 using the survey method. The surveys sent to the respondents consisted of two parts:

- The first part, consisting of 10 questions, was destined to supply the opinions of the employers regarding the possibility of recognition in the higher education of the qualifications obtained in the non-formal and informal system, especially regarding vocational qualifications.

- The second part, so-called metrics, was destined to supply the basic information regarding the companies taking part in the study, i.e. their size and legal form, and also the age and education status of the persons directly answering the questions.

The questions included in the study survey were of both open and closed character. Some of the questions required only a yes or no answer, but in many cases the respondent was asked to choose one or a few options from the presented answers. Where it was possible and seemed reasonable, the respondents were given the freedom to express their own opinions. When processing the results of the study the methods used were statistical, with a particular emphasis placed on the stratum weight.

\section{Characteristics of the studied group}

Hundred companies from the Pomorskie and Kujawsko-Pomorskie regions took part $\mathrm{n}$ the study. Each of the companies was sent one survey questionnaire with a request of filling it in. The initial analysis of the returned questionnaires showed that all of them were filled in correctly and by that were taken to the next stage of the analysis.

Out of the entities taking part in the study, the majority were small enterprises (employing between 10 and 49 persons) and medium enterprises (employing 50 to 250 persons) and the companies carrying out their business activities

${ }^{2}$ When dividing the companies to micro, small, medium and large enterprises only the criterion of the employment size was taken into account. Due to the anonymity of the survey the criterion of income was omitted. 
in the form of a limited liability company. Out of the persons who gave the answers the majority was $41-50$ years old (42\% of the respondents) and 31-40 years old (24\% respondents), and persons with higher education on a Masters' level (84\% of the respondents). The detailed information regarding the entities taking part in the study and the persons filling in the questionnaire surveys are presented in table 1.

Table 1. Characteristics of the respondents

\begin{tabular}{|c|c|c|c|c|c|c|c|}
\hline \multicolumn{2}{|c|}{ Feature } & $\mathbf{N}$ & $\%$ & \multicolumn{2}{|c|}{ Feature } & $\mathbf{N}$ & $\%$ \\
\hline \multirow{4}{*}{$\begin{array}{l}\text { Size of the } \\
\text { company }\end{array}$} & micro & 12 & 0.12 & \multirow{4}{*}{$\begin{array}{c}\text { Respondents' } \\
\text { age }\end{array}$} & Up to 30 & 16 & 0.16 \\
\hline & small & 33 & 0.33 & & $31-40$ & 24 & 0.24 \\
\hline & medium & 43 & 0.43 & & $41-50$ & 40 & 0.40 \\
\hline & large & 12 & 0.12 & & above 50 & 20 & 0.20 \\
\hline \multirow{6}{*}{$\begin{array}{l}\text { Form of legal } \\
\text { organisation }\end{array}$} & $\mathrm{LLC}$ & 34 & 0.34 & \multirow{3}{*}{$\begin{array}{l}\text { Respondents' } \\
\text { education level }\end{array}$} & Secondary & 7 & 0.07 \\
\hline & Joint stock & 12 & 0.12 & & Higher- Bachelors' & 9 & 0.09 \\
\hline & Partnership & 20 & 0.20 & & Higher - Masters' & 84 & 0.84 \\
\hline & Non-profit & 7 & 0.07 & \multirow{3}{*}{\multicolumn{4}{|c|}{$\begin{array}{l}\text { * micro enterprises - employing up to } 9 \text { persons, small- from } \\
10 \text { to } 50 \text { persons, medium - } 51 \text { to } 205 \text { persons, large - } \\
\text { above } 250 \text { person } \\
\text { ** public finance sector }\end{array}$}} \\
\hline & $\mathrm{PSE}^{\star \star}$ & 23 & 0.23 & & & & \\
\hline & other & 4 & 0.04 & & & & \\
\hline
\end{tabular}

Source: own study.

\section{Results of the study}

The study begun by finding whether the surveyed employers are interested in the process of academic recognition of the education effects obtained in the non-formal and informal system, especially with regards to vocational experience. Such situation can occur, for example, if a company employs a new employee who intends to start academic studies or if the company sends the employee to study in order that s/he supplements his/her education needed for working at a given post or allowing him/her promotion. The obtained results (graph 1) indicate that the most of the examined employers are interested in the process of recognition of their employees' qualifications in academia. Only $1 \%$ of the respondents thought differently.

Graph 1. Interest of the employers in recognition of vocational qualification of their employees in academia.

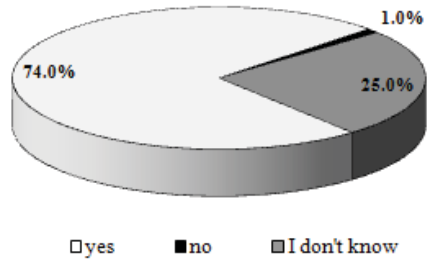

Source: own research based on the conducted study.

When analysing the obtained results in great detail it has to be emphasized that the highest percentage of the positive answers (as much as 81.8\%) was obtained from small and medium enterprises (74.4\%). The large companies were the least interested in the process of recognition of education effects (58.3\%). From the respondents' point of view the most positive approach to the recognition process was exhibited by young persons (under 30 years) and the oldest (above 50 years). In the first group the percentage of positive answers was as much as $93.8 \%$, and in the second - $80 \%$.

What is also worth pointing out is that the problem of education effects' recognition is known to some of the examined employers, because more than one-third of the respondents (43\%) confirmed that they have encountered a situation when the employee applied for being issued documents which would confirm his skills and competences acquired in the work place.

The employers were also asked if according to them the implementation of the process of education effects' 
recognition would be a motivation for the employees to embark on higher-education level studies. More than threequarters of the respondents (77\%) expressed positive opinions on this matter and the remaining number had no opinion. Special attention should be paid to the fact that none of the respondents gave a negative answer. What should also be pointed out is that the percentage of positive answers decreased with the age of the respondents. The percentage of undecided persons rose with their age. In the group of the youngest persons the percentage of positive answers was $93.8 \%$, and in the group of the oldest persons (above 50 years old) it was only $60.0 \%$. Analogically, there was only $6.2 \%$ of the youngest persons who chose the answer I have no opinion, and in the group of the oldest persons the number rose to $40 \%$.

Documenting the skills and competences acquired in the work place which could be a basis for recognising the education effects is difficult. Therefore the respondents were asked to indicate which of the listed documents, according to them, can be the basis for recognising the education effects. The respondents were also given the freedom to give their own answers. The obtained results are presented in graph 2.

Graph 2. Documents which could be the basis for recognising the education effects

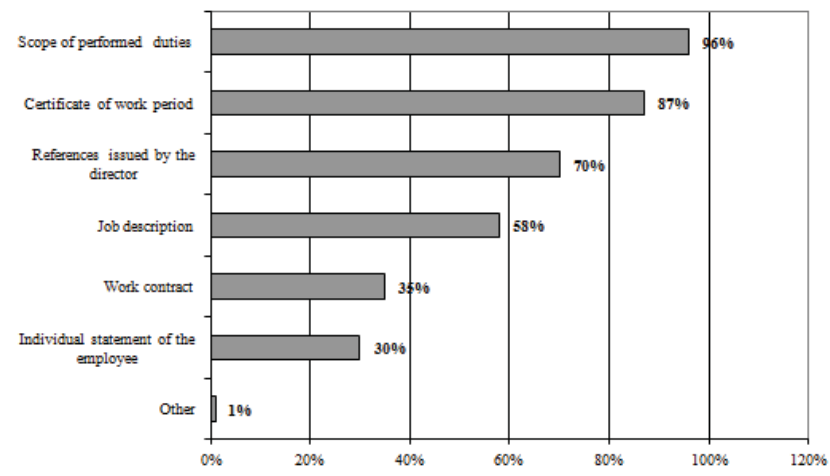

Source: own research based on the conducted study.

According to the surveyed employers, the basis of recognising the education effects can be: the scope of performed duties in the work place, certificate of work period on a given post and the references issued by the head of unit. What was indicated the least often was the content of the work contract and the individual statement of the employee. It is worth adding that one of the respondents indicated that the basis of recognising the education effects can be also the certificates of completed courses and trainings. It should be emphasized that the obtained answers did not differ depending on the size of the company (the scope of performed duties and certificate of work period were always indicated as the most important) and the age of the respondents.

Another question which the employers were asked dealt with the organisation and the course of the education effects' recognition. The employers were therefore asked if the final effect of the recognition should be exemption of the students from some of the modules which their higher education courses consisted of, or if it should simultaneously be accompanied by shortening of the studies' duration time. The obtained answers are presented in table 2.

Table 2. Final effect of the profess of education effects' recognition

\begin{tabular}{|l|c|}
\hline The process of education effects' recognition should entail: & Percentage of answers \\
\hline exemption of the students from some of the modules & $19.00 \%$ \\
\hline $\begin{array}{l}\text { exemption of the students from some of the modules and } \\
\text { shortening of the studies' duration time }\end{array}$ & $81.00 \%$ \\
\hline
\end{tabular}

Source: own research based on the conducted study.

The dominating majority of the respondents, as much as $81 \%$ believes that as a result of the implementation of the education effects' recognition system the student should be jest exempted from some of the modules with simultaneous shortening of the studies' duration time. Only $19 \%$ of the respondents were against shortening of the studies' duration. 
The employers were also asked if the process of education effects' recognition should take into account all of the students regardless of their age and the length of their work experience, or whether it should be somehow limited. The obtained answers are presented in table 3.

Table 3. Limitations in the process of education effects' recognition

\begin{tabular}{|l|c|}
\hline Who can be affected by the process of education effects' recognition: & Percentage of answers \\
\hline Everyone, regardless of their work experience and age & $62.00 \%$ \\
\hline Only the students above the age of 25 & $0.00 \%$ \\
\hline Only the students above the age of 25 who have at least 3 years of work experience & $38.00 \%$ \\
\hline
\end{tabular}

Source: own research based on the conducted study.

According to the presented results almost two-thirds of the employers believe that the process of education effects' recognition can take into account all students. On the other hand, $38 \%$ of the respondents believe that the process should be limited to the students above the age of 25 who have at least 3 years of work experience. It should also be pointed out that the obtained answers did not differ depending on the size of the enterprise, but a significant difference was noted depending on the age of the respondents. $77.7 \%$ of the persons aged 31 to 40 believed, contrary to the other groups, that the process of education effects' recognition should be applied only to students above the age of 25 who have at least 3 years of work experience. Only $22 \%$ of this group believed that the process of recognition should not have any limitations.

The next question was destined to deliver information whether the process of education effects' recognition should be applied to all the stages of the higher education, i.e. the undergraduate degree (Bachelors'), postgraduate degree (Masters'), research degrees (Doctoral studies) and other postgraduate courses, and also whether this process should include all the modules carried out during the studies or only a part of them. The obtained results are presented on the graphs 3 and 4.

Graph 3. Modules/subjects incorporated into the system of education effects' recognition

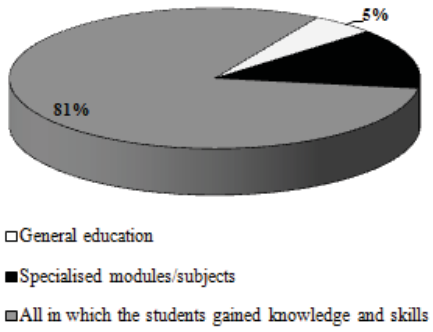

Source: own research based on the conducted study.

Graph 4. Stages of higher education in which the process of education effects' recognition should be implemented

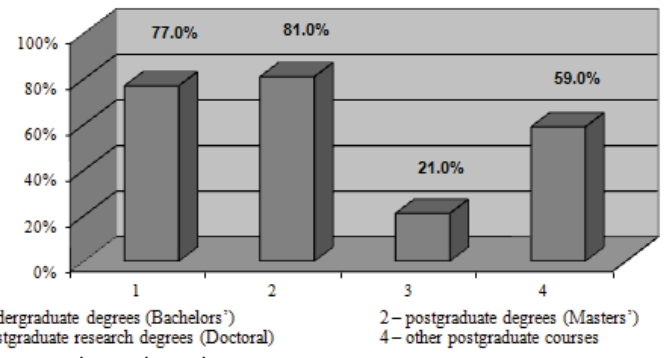

Source: own research based on the conducted study. 
According to the employers, the recognition of the education effects should foremost be applied to all of the undergraduate and postgraduate studies on Masters' level- such an opinion was expressed by $77 \%$ and $81 \%$ of the respondents, respectively. The types of studies least often indicated were the postgraduate research studies, which is in accordance with their specifics. Furthermore, the significant majority of the employers also believed that the process of education effects' recognition should incorporate all of the modules/subjects thought in higher education and that it should not be limited to a single group, e.g. general subjects or specialised subjects. The obtained answers did not differ depending on the size of the examined enterprise or the age of the respondents.

The final question asked of the respondents who should be making the decisions regarding recognising the competences and skills obtained in the non-formal and informal system. Whether it is the higher education institution which should be responsible, or maybe other non-governmental organisations set up especially for this purpose, who would act across the whole territory of the country, or a central unit (e.g. Commission for Recognition) created within the structures of the Ministry of Science and Higher Education. The obtained results are presented in table 4.

Table 4. Institutions responsible for the realisation of the education effects' recognition process

\begin{tabular}{|l|c|}
\hline The process of education effects' recognition should be realised by & Percentage \\
\hline Higher education institutions - independently and automatically & $6.00 \%$ \\
\hline Non-governmental organisations act across the whole territory of the country & $5.00 \%$ \\
\hline $\begin{array}{l}\text { A Commission for Recognition created within the structures of the Ministry of } \\
\text { Science and Higher Education }\end{array}$ & $28.00 \%$ \\
\hline
\end{tabular}

Source: Own research based on the conducted study.

More than two-thirds of the examined employers believed that the decisions regarding recognition of the education effects' recognition should be made independently and autonomously by the higher education institution. On the other hand, slightly more than a quarter of the respondents believed that such decisions should be taken on a central level by an institution created especially for this purpose within the structures on the Ministry of Science and Higher Education.

\section{Summary and results}

Based on the survey carried out among the employers regarding the possibility of recognising within the higher education the knowledge, skills and competences obtained in the non-formal and informal systems, with a special emphasis being put on the vocational qualifications, following conclusions can be made:

- the employers are interested in implementing the process of education effects' recognition - as much as $74 \%$ of the respondents expressed this opinion. What is more, $77 \%$ of the employers believe that the possibility of recognising the vocational qualifications in the higher education would be a motivational factor for pursuing an education in the formal system.

- the main documents which can constitute the basis for recognising the education effects in the higher education are: the scope of duties performed in the work place (96\%), certificate of work period on a given work post (87\%) and references issued by the head of the unit (70\%).

- $\quad$ according to most of the employers (81\%), the process of education effects' recognition should not only entail exempting the students from some of the subjects/modules, but also shortening the time of their studies. Furthermore, two-thirds believe that this process should incorporate all of the students, without introducing any additional limitations regarding their age or the length of their work experience.

- the decisions regarding recognising the education effects should be taken autonomously by higher education institutions. This is the opinion of $67 \%$ of the examined respondents. $28 \%$ of the employers were favouring the appointment of a central institution within the structures of the Ministry of Science and Higher Education (e.g. a Commission for Recognition).

What should be emphasised is that the employers are interested in the implementation of the recognition process in the higher education, which can contribute to propagating lifelong learning and, in many cases, can lead to activation on the work market. 


\section{References}

W. Horynia, J. Maciejewski (ed.), Andragogika w ujęciu interdyscyplinarnym, Wydawnictwo Uniwersytetu Wrocławskiego, Wrocław 2007.

E. Cresson, P. Flynna, Biała księga kształcenia i doskonalenia. Nauczanie i uczenie się na drodze do uczącego się społeczeństwa, Warszawa 1997.

S. E. Eaton, Formal, non-formal and informal learning: The case of literacy, essential skills and language in Canada, Calgary, 2010. 